\title{
Correction to: Effects of vasopressin on anesthetic response time and circulatory dynamics of lidocaine
}

\author{
Shoko Fujimori ${ }^{1} \cdot$ Katsuhisa Sunada $^{1}$
}

Published online: 5 March 2021

(c) The Author(s) 2021

\section{Correction to: Odontology \\ https://doi.org/10.1007/s10266-020-00585-x}

In the original publication of the article, an unwanted asterisk was found in Fig. 3. The correct Fig. 3 is provided below.

The original article has been updated.

Open Access This article is licensed under a Creative Commons Attribution 4.0 International License, which permits use, sharing, adaptation, distribution and reproduction in any medium or format, as long as you give appropriate credit to the original author(s) and the source, provide a link to the Creative Commons licence, and indicate if changes were made. The images or other third party material in this article are included in the article's Creative Commons licence, unless indicated otherwise in a credit line to the material. If material is not included in the article's Creative Commons licence and your intended use is not permitted by statutory regulation or exceeds the permitted use, you will need to obtain permission directly from the copyright holder. To view a copy of this licence, visit http://creativecommons.org/licenses/by/4.0/.

Publisher's Note Springer Nature remains neutral with regard to jurisdictional claims in published maps and institutional affiliations.

The original article can be found online at https://doi.org/10.1007/ s10266-020-00585-x.

Shoko Fujimori

shokosakura0805@gmail.com

1 Department of Dental Anesthesiology, The Nippon Dental University School of Life Dentistry at Tokyo, 1-9-20, Fujimi,

Chiyoda-ku, Tokyo 102-8159, Japan 
640

Odontology (2021) 109:639-640

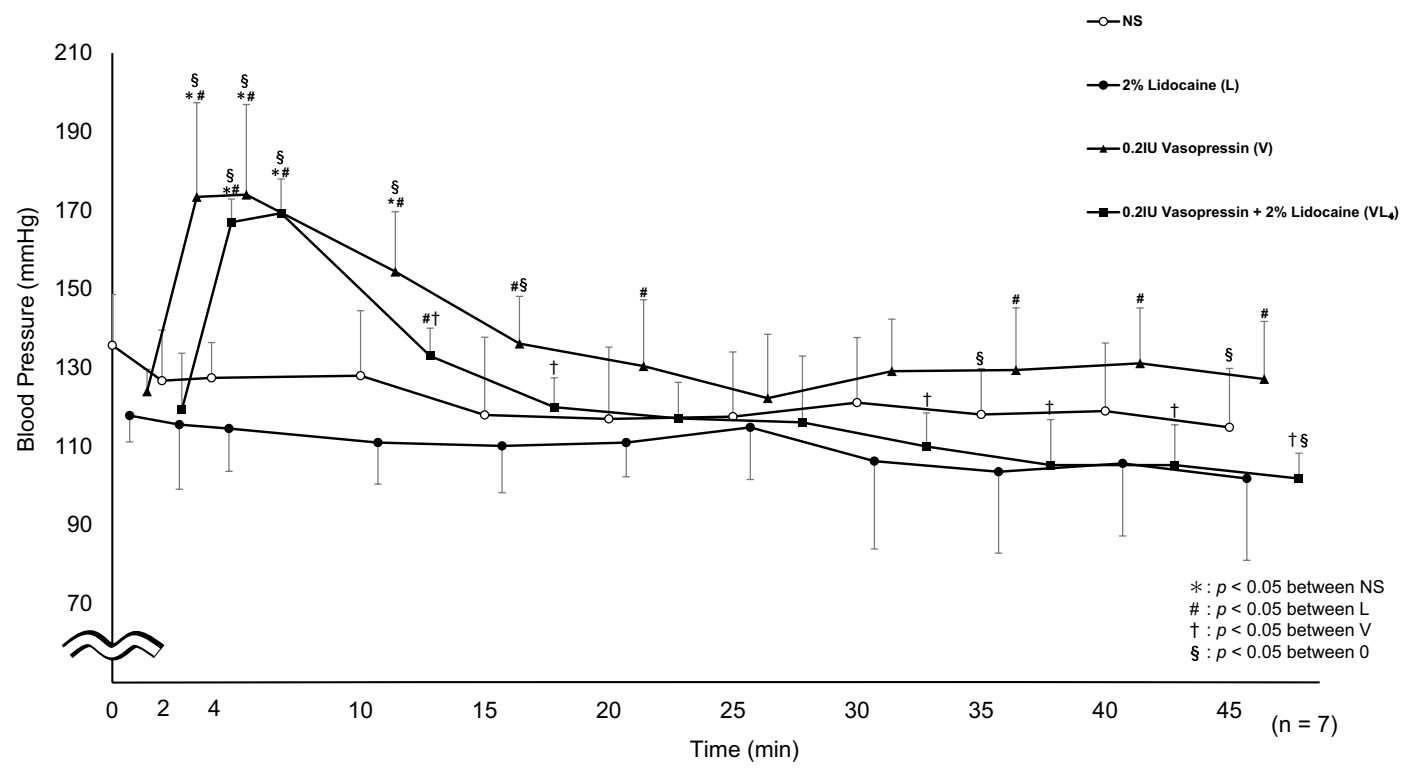

Fig. 3 Systolic blood pressure. Significantly higher values were seen in VL4 at 2, 4, and $10 \min (p<0.0001, p<0.0001, p=0.0011$, respectively) compared to L. VL4 was significantly elevated at 2,4 , and $45 \min (p<0.0001, p<0.0001, p=0.0192$, respectively) compared to 0 min

Springer 